\title{
Property Taxes and Urban Housing Abandonment ${ }^{1}$
}

\author{
Michelle J. White \\ Department of Economics, University of Michigan, Ann Arbor, Michigan 48109
}

Received September 25, 1984; revised March 4, 1985

\begin{abstract}
This paper formulates and estimates an economic model of landlord housing abandonment, using New York City data. A major focus of the study is to investigate the importance of property taxes in the abandonment decision, as opposed to such factors as the types of buildings or the characteristics of households occupying the neighborhood. There are two major results: first, cities can reduce the rate of abandonment by initiating foreclosure as soon as buildings go into arrears on property tax payments (rather than allowing a grace period), and second, property taxes are an important and significant determinant of abandonment rates. The benefits and costs of a policy whereby cities would systematically reduce property taxes in blighted neighborhoods by lowering assessment levels are also explored. (1) 1986 Academic Press, Inc.
\end{abstract}

\section{INTRODUCTION}

Housing abandonment - the voluntary relinquishing of ownership by private landlords of rental property - is frequent in many U.S. cities but has costly consequences for city governments. It is difficult to document since most available data refer to a different, although related, phenomenon - that of buildings becoming uninhabited by tenants. While landlord and tenant abandonment often occur simultaneously, they may not, and buildings may be owned but unoccupied or no longer owned but still occupied.

Desertion of central city neighborhoods by their inhabitants is tied to the trend toward suburbanization and declining population of central cities. The result is that some urban housing units are no longer used. Ownership abandonment, however, is a narrower problem and a more immediate economic decision. Each period landlords can choose to continue owning and operating marginal buildings or to abandon them according to which alternative leaves the landlord better off.

Economists who have studied "slum" housing markets suggest that ownership abandonment is not a random or unexpected event, but a

\footnotetext{
${ }^{1}$ I am grateful to Bruce Bender, Ted Bergstrom, Howard Chernick, Paul Courant, Roger H. Gordon, Dick Netzer, John Yinger, and the referee for helpful comments, and to Donald Negri and Robert Levinson for research assistance. This paper was made possible in part by funds granted by the Charles $H$. Revson Foundation and the Sloan Foundation to the Urban Research Center, New York University, where the author is a Visiting Research Associate. The statements made and views expressed, however, are solely the responsibility of the author.
} 
planned occurrence. These markets are said to attract specialized entrepreneurs for whom ownership abandonment is but the last step in a planned process of deferring maintenance, dropping services, and generally trading off immediate profits against a lengthening of the owned lifetime of the building. Salins [6] and Sternlieb and Burchell [12] suggest that landlords follow a particular order in reducing expenses. First, they delay or drop nonessential repairs. Second, they default on mortgage obligations. This may lead to foreclosure by the lender, but often does not if the lender does not wish to own the building. Third, property tax payments are stopped. This starts a timetable for loss of ownership, since cities take over properties whose taxes are in arrears for a certain number of years, usually 1 to 3 . Thus the decision to cease paying property taxes is a decision to abandon the building, once the tax arrears exceed the city's foreclosure period. $^{2}$

This paper explores and estimates an economic model of the decision to abandon ownership of housing, using data from New York City. New York City is particularly well-suited to studying ownership abandonment, since it has a widespread abandonment problem as well as data concerning properties in arrears on taxes. During the late 1970s, about $14 \%$ of all residential properties in the city were in arrears on taxes by 9 months or more but were not yet taken over by the city. ${ }^{3}$

A major focus of the paper is to explore the importance of property taxes in the abandonment decision, as opposed to such factors as the physical characteristics of buildings being abandoned or the characteristics of people occupying the neighborhood. This is an important policy issue, since property taxes are determined by cities themselves. Many U.S. central cities have assessment patterns which change infrequently. Since poor neighborhoods are likely to have stagnant or declining property values, effective property tax rates often rise relative to value and even rise in absolute value (due to statutory tax rate increases) as buildings age and neighborhoods decline. In many such areas, property taxes constitute the largest operating expense. ${ }^{4}$ This encourages ownership abandonment. But abandonment is expensive for cities, since either the city itself must become the landlord of abandoned buildings or the abandonment of ownership leads to withdrawal

\footnotetext{
${ }^{2}$ Peterson [3] and Peterson et al. [4] present an alternative view of the abandonment process which stresses the unwillingness of small owners to invest in or to maintain properties on which they have incurred unforeseen capital losses. Also see Stegman [9] and [10].

${ }^{3}$ For tax purposes a single property could be a one- or two-family house, a rental or cooperative apartment building, or a condominium apartment. Since abandonment rates are generally lower for single-family houses and small buildings, the number of abandoned housing units probably exceeds the $14 \%$ figure. For data sources, see below.

${ }^{4}$ Sternlieb and Burchell [12] suggest that property taxes were about $35 \%$ of rents in a sample of slum buildings in Newark, N.J., in 1971. For earlier data, see Sternlieb [11].
} 
of services (heat, utilities) and desertion by tenants. In the former case, the city itself must operate the building and may end up making repairs that have been neglected by private landlords, even though rent payments do not cover costs. In the latter case, the city must bear the cost of rehousing former tenants and of demolishing or boarding up vacant buildings. ${ }^{5}$ Thus an important policy issue is whether systematic downward reassessment of properties in blighted neighborhoods can benefit cities by reducing ownership abandonment. ${ }^{6}$ This either could be part of a general move toward assessing property taxes as a uniform percentage of market value for all properties, or could be a more limited change in which taxes would be lowered in neighborhoods where abandonments occur but the general pattern of property tax administration would remain unchanged.

Section II poses a theoretical model of owners' decisions to abandon buildings. Section III describes the data and the empirical model and presents results. Section IV considers the benefits and costs of a policy of discouraging landlord abandonment of housing by systematically reducing property tax assessments in declining neighborhoods.

\section{THE ABANDONMENT DECISION}

Suppose that the production function for housing is

$$
Q=Q(K, D) ; Q_{K}>0, Q_{D}<0, Q_{K K}, Q_{D D}<0,
$$

where $Q$ is housing quality per housing unit, $K$ is capital per housing unit, and $D$ is density (or dwelling units per unit of land). $Q_{K K}<0$ implies that extra capital has a declining positive effect on housing quality and $Q_{D D}<0$ implies that extra density has an increasing negative effect on housing quality.

Housing quality is assumed to depreciate exponentially at a rate $d$ per unit of time. The rate of depreciation depends positively on a vector of attributes of the neighborhood, denoted $G$, and negatively on the amount of maintenance. Maintenance per housing unit per unit of time is denoted $m$, so that $d=d(m, G)$ and $d_{m}<0$. The price per unit of maintenance is $p_{m}$. The rent per unit of housing quality per unit of time, $P$, is also assumed to vary with the vector of neighborhood attributes, $G$. Thus $P=P(G)$ and $P_{G}>0$.

\footnotetext{
${ }^{5}$ New York City does not attempt to collect unpaid property taxes from owners of buildings that is has taken over.

${ }^{6}$ Peterson et al. [4] argue that property taxes are not an important factor in ownership abandonment because by the time properties are lost to foreclosure, owners have not been paying taxes for several years. However, the model posed below argues that taxes are nonetheless an important factor in the abandonment decision, since the grace period until foreclosure is fixed. Taxes therefore have their effect with a lag.
} 
The cost of capital per unit per year, $p_{k}$, is constant. Property taxes per housing unit, $T$, are assumed to depend on neighborhood quality variables and on the level of capital per housing unit. Thus $T=T(G, K)$ and $T_{K}>0$. We neglect the effect of taxes other than property taxes. Land value per unit is $L$.

Owners of vacant lots are assumed to maximize discounted future profits in choosing the best land use. For the lot owner who decides to build new housing on his lot, discounted profit is maximized over $K, D$, and $m$ to determine the optimal quality and density of housing and the optimal spending on maintenance, given the exogenous attributes of the neighborhood, $G$. This gives the profit function

$$
\max _{K, D, m} \int_{0}^{\infty}\left(e^{-(r+d) r} P Q D-e^{-r t}\left(D T+p_{k} K D+m p_{m} Q D\right)\right) d t .
$$

The first term in (2) is rental income, the second is property taxes, the third is the cost of capital, and the fourth is the cost of maintenance. Rent receipts decline at rate $d$ over time, both because of the decline in the building's quality over time and because there is a higher vacancy rate as the building deteriorates. Future rent receipts, taxes, maintenance and capital costs all are discounted at rate $r{ }^{7}$

Substituting (1) into (2) and differentiating, we can solve for the optimal levels of quality and density at time $t, K_{t}^{*}$ and $D_{t}^{*}$, as a function of the price per unit of housing at time $t$, or

$$
K_{t}^{*}=K\left(P_{t}\left(G_{t}\right)\right) \text { and } D_{t}^{*}=D\left(P_{t}\left(G_{t}\right)\right) .
$$

However, for the owner of a building already constructed, the quality and density levels are given and the main variables under the owner's control are the maintenance expenditures and the date of abandonment or reconstruction of the building. For existing buildings, the exogenous levels of quality and density may be inappropriate for the neighborhood's current attribute level and housing prices, which are likely to have changed since the building was built.

Suppose that neighborhood quality has risen since the building was built. Then the rise in rents implies that it is worthwhile to rebuild or renovate the building at a higher quality level and probably a higher density level, either immediately or in the future. ${ }^{8} \mathrm{~A}$ large divergence between actual versus optimal levels of $K$ and $D$ often is associated with outbreaks of arson, since a hot fire permits immediate readjustment.

\footnotetext{
${ }^{7}$ See Smith [8] and Bender [1] for discussion and development of a similar model.

${ }^{8}$ Bender [2] derives the comparative statics properties of (3). If $Q_{K D}=0$, then $d K / d P$ is positive under reasonable conditions and $d D / d P$ is also positive under somewhat more stringent conditions. If $Q_{K D} \neq 0$, then both signs are indeterminate.
} 
If the neighborhood quality has fallen since the building was built, then the owner may wish to abandon it at some point in the future. Abandonment will be planned if at the current level of rents in the neighborhood, $P_{t}=P\left(G_{t}\right)$, it is not worthwhile either for the owner to rebuild or renovate the building at any feasible quality and density level or for the owner to spend enough to maintain the building indefinitely at its current quality and density level. In this case the timing of the planned abandonment is the major decision made by the owner.

We now turn to an analysis of this decision. Assume that an existing building will be abandoned at some point in the future, because neighborhood quality has declined since it was built. The owner decides when to abandon it so as to maximize the discounted present value of rents minus property taxes during the remaining period over which the building is held. The abandonment process is initiated by the owner ceasing to pay property taxes. The city then allows a fixed number of years of tax arrears to accumulate before it forecloses on the property. Define $t=0$ as the present, $t=t_{A}$ as the abandonment date or the date when the owner stops paying taxes, and $t=t_{A}+g$ as the foreclosure date when the city takes over the building. The length of the grace period, $g$, between abandonment and foreclosure is exogenously determined by each city.

In modeling abandonment, we simplify the model by assuming that the depreciation rate is fixed and that maintenance expenditures are zero. (The latter is equivalent to assuming that rent receipts by the landlord are net of maintenance costs.) This assumption is made to avoid introducing extra unobservable variables into the model to be estimated. With this simplification, Fig. 1 shows the pattern of nominal rents and taxes per housing unit over time. For given levels of capital per housing unit $(K)$ and neighborhood quality $(G)$, rents decline exponentially at rate $d$ and taxes are assumed to remain constant. The period over which the owner holds the building is divided into an initial period from $t=0$ to $t_{A}$, when taxes are paid, and the grace period from $t=t_{A}$ to $t_{A}+g$, when no taxes are paid.

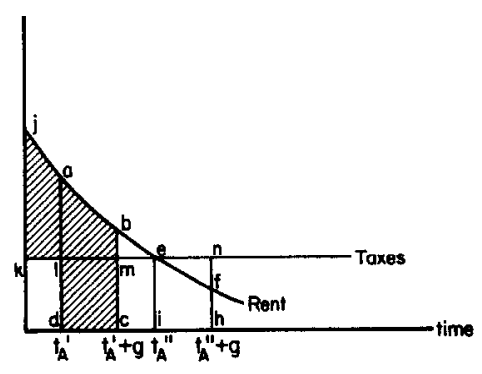

FIGURE 1 
As shown, the owner ceases paying taxes at $t_{A}=t_{A}{ }^{\prime}$ when rents still exceed taxes. Profits are shown as the shaded area. ${ }^{9}$

The owner's problem is therefore to set $t_{A}$ so as to maximize market value $(M V)$, which equals discounted future rents minus taxes, or

$$
M V=\int^{t_{1}+g}\left(e^{-(r+d) t} P Q D\right) d t-\int^{t_{1}}\left(e^{-r t} D T\right) d t .
$$

The first term in (4) is rents, which are received from the present until $t=t_{A}+g$, and the second term is property taxes, which are paid from the present to $t=t_{A}$. We assume that the owner has already ceased making payments on the building's mortgage, if any. (The decision to abandon mortgage payments could be modeled explicitly using a similar approach.)

The first- and second-order conditions for profit maximization are

$$
\begin{gathered}
e^{-d\left(t_{A}+g\right)} P Q D=e^{-r t_{A}} T D \quad \text { and } \\
(-d) e^{-d t_{A}-(r+d) g} P Q D<0 .
\end{gathered}
$$

Equation (5) says that at the optimal time of abandonment, the gain from retaining ownership of the building one period longer, which means that one more period of rents is received $g$ periods in the future, should be just offset by the fact that one period more of taxes must be paid immediately. At the time of abandonment, the extra rent payment to be received $g$ periods in the future is $e^{-(r+d)\left(t_{A}+g\right)} P Q D$, while the extra tax payment paid immediately costs $e^{-r t} A T$. As long as the grace period is positive, it is profitable to abandon the building when current rents exceed current taxes, as shown by the shaded area in Fig. 1. Equation (6) says that in addition, rents should be declining faster than taxes. (The latter is always satisfied given the exponentially declining rent function and the constant taxes assumed here.)

This result seems somewhat counterintuitive. However, suppose that we compare the profitability from a landlord's standpoint of abandoning a building at $t=t_{A}^{\prime}$, as shown in Fig. 1, with abandoning it at the later point $t=t_{A}^{\prime \prime}$, where rents equal taxes. If abandonment occurs at $t_{A}^{\prime \prime}$, then the owner earns profits equal to the areas $j k e+e f h i$. But if abandonment occurs earlier at $t_{A}^{\prime}$, then the owner receives the shaded areas jalk + abcd. Since the value of taxes not paid is the same in both cases $(l m c d=e n h i)$, it is therefore more profitable to abandon earlier at $t_{A}^{\prime}$ since the triangle enf is larger than the triangle bem.

\footnotetext{
${ }^{9}$ Although owners are not actually paying property taxes at the time the city forecloses on their buildings, property taxes are nonetheless an important determinant of the abandonment decision.
} 
A further point is that according to Fig. 1, it is actually optimal to set the date of abandonment $g$ periods before the intersection of the tax and rent curves, so that the grace period ends exactly at the intersection. This is because in the diagram the interest rate, $r$, is assumed to be zero. With a positive interest rate, the optimal abandonment date is earlier, as at $t_{A}^{\prime}$.

Solving (5) for $t_{A}$, we get

$$
t_{A}=-\frac{1}{d}\left[\ln \left(\frac{T D}{P Q D}\right)+g(r+d)\right] .
$$

From (7), for the owner to hold the building at all; i.e., for $t_{A}>0$, initial taxes must be less than initial rents (or $T D / P Q D<1$ ).

How does varying the length of the grace period affect the timing of abandonment? Differentiating (7), we find that $\partial t_{A} / \partial g<0$; i.e., the shorter the grace period, the later is the optimal date of abandonment. Landlords profit from the grace period, because while it is running they collect rents but pay no taxes. Since rent receipts fall over time, the grace period is more profitable the earlier it starts. But the longer the grace period, the larger the landlords' incentive to start it early while rents are relatively high. Conversely, a shorter grace period makes it worthwhile for landlords to continue ownership longer, since the profitable period when no taxes are paid is shorter and foreclosure comes sooner. At the limit if the grace period is zero, then landlords continue ownership until profits equal zero.

The length of the grace period is determined by each city. In Chicago it is 2 years. In New York, it was recently reduced from a minimum of 3 years to 1 year for large buildings. The apparent motivation for reducing the period in New York was that with faster foreclosure, abandoned buildings would be in better condition at the time of takeover and would therefore be less expensive for the city to repair and operate and be easier to sell. However, the analysis above suggests that a shorter grace period should also reduce the number of abandonments. From the viewpoint of cities, the optimal grace period clearly is zero, i.e., immediate initiation of foreclosure proceedings as soon as property taxes go into arrears. ${ }^{10}$

We can also examine the effect on abandonment incentives of a policy of reducing assessment levels of blighted buildings by some arbitrary amount. Since $\partial t_{A} / \partial T D<0$, the optimal abandonment date is later if a building's assessment (and therefore its tax liability) is lower. We investigate this effect empirically below.

\footnotetext{
${ }^{10} \mathrm{~A}$ grace period of zero might be administratively infeasible, since cities often make mistakes in sending out property tax bills and recording receipt of payment. Also any shortening of the grace period involves transition problems not considered here, since it makes eligible for immediate foreclosure many buildings whose owners may not have intended to abandon them.
} 


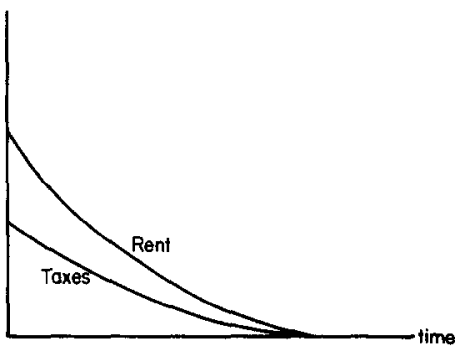

FIGURE 2

Finally, suppose that the property tax system were changed in a more fundamental way, so that taxes were a fixed proportion of rent minus maintenance costs (or a different fixed proportion of market value). Figure 2 shows this possibility. Here there would be no incentive for an owner to abandon a building as long as rent minus maintenance costs is positive. Property taxes would not accelerate abandonment of buildings. Owners would hold on to their buildings as long as rent levels were positive. A property tax system of this sort is probably ideal, while the proposed policy of reducing assessments on properties in blighted neighborhoods by an ad hoc amount is second-best. Given the importance of the abandonment problem and the reluctance of cities to allow property assessments to change very much, however, it seems important to explore the effects of second-best policy options which involve less radical change. ${ }^{11}$

\section{DATA AND ESTIMATION}

Proceeding toward an empirical specification, we know that the condition for abandonment in a continuous time context is that (5) must hold at the time of abandonment. We also know that the market value of a building equals the sum of its discounted future stream of net rents minus property taxes. Thus, from (4),

$$
M V=-\frac{P Q D}{(r+d)}\left[e^{-(r+d)\left(t_{A}+g\right)}-1\right]+\frac{T D}{r}\left[e^{-r t_{A}}-1\right] .
$$

The data set to be used in the estimation includes information on average market value and average property taxes for buildings in neighborhoods in

\footnotetext{
${ }^{11}$ Note that lowering the assessments of properties in neighborhoods where abandonments are likely would not violate the legal requirement in many states that assessed value/market value ratios and effective property tax rates must be the same in all neighborhoods. Since the value of buildings in these neighborhoods has probably been falling, a lower assessment is necessary to keep the effective property tax rate from rising.
} 
New York City, but no information on average rent levels. However, (7) and (8) form a set of simultaneous equations involving the known variables $T D_{i}$ and $M V_{i}$ (where $i$ denotes an individual neighborhood), the parameters $g, d$, and $r$, and the unknown variables $t_{A_{i}}$ and $P Q D_{i}$. Substituting values for the parameters, we can use numerical techniques to solve for the average values of $t_{A_{i}}$ and of $P Q D_{i}$ for each neighborhood. The solution for $P Q D_{i}$ in general form is

$$
P Q D_{i}=f\left(M V_{i}, T D_{i}, r, g, d\right) .
$$

If the true average value of rent in neighborhood $i$ is $\overline{P Q D}_{i}$, then we assume that the calculated value $\widehat{P Q D}_{i}$ is related to the true average value by the following:

$$
\overline{P Q D}_{i}=\overline{P Q D}_{i}+\eta_{i}
$$

where $\eta_{i}$ is a random error term having mean zero which is uncorrelated with $\widehat{P Q D}_{i}$.

For an individual building $j$ in neighborhood $i$, abandonment occurs or has already occurred if (5) is zero or negative at $t=t_{A}=0$ or

$$
e^{-(r+d) g} P Q D_{i j}-T D_{i j} \leq 0 .
$$

Suppose that an estimate of (11) for building $j$ in neighborhood $i$ is provided by evaluating (5) using the average level of property taxes for neighborhood $i, T D_{i}$, and the true average value of rents for neighborhood $i, \overline{P Q D}_{i}$. Then we have

$$
e^{-(r+d) g} P Q D_{i j}-T D_{i j}=e^{-(r+d) 8} \overline{P Q D}_{i}-T D_{i}-\varepsilon_{i j},
$$

where $\varepsilon_{i j}$ is a random error term having mean zero. For abandonment to be worthwhile, it must be the case that

$$
e^{-(r+d) g} \overline{P Q D}_{i}-T D_{i} \leq \varepsilon_{i j} .
$$

Suppose that the $\varepsilon_{i j}$ terms are distributed according to the Weibull distribution. Then the probability of an individual building being abandoned could be expressed as

$$
\begin{aligned}
\operatorname{Prob} & {\left[\left(e^{-(r+d) g} \overline{P Q D}_{i}-T D_{i}\right) \leq \varepsilon_{i j}\right] } \\
= & \frac{\exp \left[b\left(e^{-(r+d) g} \overline{P Q D}_{i}-T D_{i}\right)\right]}{1+\exp \left[b\left(e^{-(r+d) 8 \overline{P Q D}_{i}}+T D_{i}\right)\right]} .
\end{aligned}
$$

This expression can be estimated using the logit technique. 
However, the available data do not pertain to individual buildings, but to the average characteristics of buildings and the aggregate rate of abandonment in different neighborhoods. An aggregation or grouping procedure is therefore necessary. Since (13) describes the probability that an individual building will be abandoned conditional solely on neighborhood characteristics, it also describes the forecast for the percentage of buildings in neighborhood $i$ that will be abandoned. Given the model, the percentage abandoned will have a multinomial distribution around this mean with an extremely tight distribution, since the number of buildings in each neighborhood is large. Given the large number of buildings, the variance of the error of our forecast for the percentage abandoned should be trivial. However, we observe not $\overline{P Q D}_{i}$, but $\overline{P Q D}_{i}$. Conditional on what we observe, the actual percentage of buildings abandoned in neighborhood $i$ can be expressed as

$$
\rho_{i}=\frac{\exp \left[b\left(e^{-(r+d) g}\left(\widehat{P Q D}_{i}+\eta_{i}\right)-T D_{i}\right)\right]}{\left.1+\exp \left[\beta\left(e^{-(r+d) g} \widehat{P Q D}_{i}+\eta_{i}\right)-T D_{i}\right)\right]}
$$

Collecting terms in (14), we get the equation to be estimated:

$$
\log \frac{\rho_{i}}{1-\rho_{i}}=b\left(e^{-(r+d) g} \widehat{P Q D_{i}}-T D_{i}\right)-b e^{-(r+d) g_{\eta_{i}}} .
$$

Note that unlike most logit equations, (15) contains no constant term.

One problem with the above derivation, ignored previously for simplicity, is that larger buildings having more apartments will have higher values of $\widehat{P Q D}_{i}, \widehat{P Q D}_{i}$, and $T D_{i}$, and presumably will have higher variances of $\varepsilon_{i j}$ and of $\eta_{i}$. Yet a critical assumption of (13) is that $\varepsilon_{i j}$ is homoscedastic. In deriving our final specification, we assume that the standard deviations of both $\varepsilon_{i j}$ and $\eta_{i}$ are proportional to $T D_{i}$ and then correct for heteroscedasticity by dividing the rent and tax terms in (14) by $T D_{i}$. Given this specification, (14) becomes

$$
\rho_{i}=\frac{\exp \left[\beta\left(e^{-(r+d) g}\left(\left(\widehat{P Q D}_{i}+\eta_{i}\right) / T D_{i}\right)-1\right)\right]}{1+\exp \left[\beta\left(e^{-(r+d) g}\left(\left(\widehat{P Q D}_{i}+\eta_{i}\right) / T D_{i}\right)-1\right)\right]}
$$

where the error term is now $b e^{-(r+d) g}\left(\eta_{i} / T D_{i}\right)$, which we have assumed to be homoscedastic. ${ }^{12}$ From $\left(14^{\prime}\right)$ we get as the equation to be estimated:

$$
\log \frac{\rho_{i}}{1-\rho_{i}}=\beta\left(e^{-(r+d) g} \frac{\widehat{P Q D_{i}}}{T D_{i}}-1\right)+\beta e^{-(r+d) g} \frac{\eta_{i}}{T D_{i}}
$$

${ }^{12}$ See Pindyck and Rubinfeld [5]. 
Finally, an additional heteroscedasticity problem is that the variance of the error term is likely to be related to characteristics of each neighborhood's resident population and to characteristics other than size of its buildings. For example, a neighborhood having large numbers of families receiving public assistance is likely to have more low-value buildings and therefore a larger proportion of negative error terms. The same may be the case for neighborhoods with more undesireable building types, such as "old law tenements" and other old or walkup apartment buildings. ${ }^{13}$

Suppose therefore that $G_{i}$ is a vector of neighborhood variables related to the error variance in $\left(15^{\prime}\right)$. Specifically, assume that the standard deviation of the error term in $\left(15^{\prime}\right)$ varies directly with $1 / b^{\prime \prime} G_{i}$, where $b^{\prime \prime}$ is a new vector of parameter values including a constant term $b_{0}^{\prime \prime}$. The equation to be estimated then becomes

$$
\begin{aligned}
\log \frac{\rho_{i}}{1-\rho_{i}}= & b_{0}^{\prime \prime}\left(e^{-(r+d) g} \frac{\widehat{P Q D_{i}}}{T D_{i}}-1\right) \\
& +b_{1}^{\prime \prime} G_{1}\left(e^{-(r+d) g} \frac{\widehat{P Q D_{i}}}{T D_{i}}-1\right) \\
& +b_{2}^{\prime \prime} G_{2}\left(e^{-(r+d) g} \frac{\widehat{P Q D_{i}}}{T D_{i}}-1\right) \\
& +\cdots+\gamma_{i j}^{\prime},
\end{aligned}
$$

where $\gamma_{i j}$ is the new homoscedastic error term. We present results below for both $\left(15^{\prime}\right)$ and $\left(15^{\prime \prime}\right) .{ }^{14}$

The dependent variable used in the regressions is the probability of a building in neighborhood $i$ being abandoned by its owner, as measured by its being in arrears on property taxes but not yet taken over by the city. At the time period to which the data refers, New York could not foreclose on buildings until they were at least 3 years in tax arrears. Also, because foreclosures in each borough occurred only at discrete intervals of about 2

13، Old law tenements" are apartment buildings built before 1901. They were not required to have separate kitchen or bathroom facilities in each apartment, were walkups, and had virtually complete coverage of the lot by the building.

${ }^{14}$ It should be noted that if payment of property taxes and of a mortgage are dropped simultaneously (rather than the mortgage payment being dropped sooner as assumed here), then the estimated effect of a property tax reduction on the probability of abandonment may be biased. From the theoretical development above, if both payments are dropped simultaneously but the date of foreclosure remains unchanged, then owners have an incentive to abandon their buildings (i.e., to set $t_{A}$ ) at an earlier date. But the effect of lowering property tax liability on the date and probability of abandonment would depend on whether the private lender then changed its behavior and foreclosed first. 
years, the average grace period could be expected to stretch for about 4 years.

An important issue here is the definition of when buildings are abandoned. In the model, profits accruing during the grace period (when rents are received but no taxes are paid) are an important factor in the decision to abandon. This suggests that the abandonment decision is made at the time a building first goes into tax arrears. However, until the city actually forecloses on the building, the decision to abandon is reversible, since ownership can be retained by paying off the tax arrears. The model suggests that once it is worthwhile to start the abandonment process by ceasing to pay taxes, it is not generally worthwhile to reverse the decision, especially if cities charge penalties as well as interest for late payment of taxes. However, owners having cash flow problems may defer paying taxes because even a high-interest loan from the city is valuable. These owners may have no intention of abandoning their buildings. In addition, if neighborhood conditions $\left(G_{i}\right)$ improve, then it could be worthwhile to reverse an earlier decision to abandon.

The units of observation used in the regressions are neighborhoods in New York City, of which there are about $260 .{ }^{15}$ For each neighborhood, the following data were obtained concerning buildings in tax arrears: the percentage of buildings which were between 9 and 17 months in tax arrears, the percentage of buildings between 18 months and 3 years in tax arrears, and the percentage of buildings more than 3 years in tax arrears. The percentage of buildings between 18 months and 3 years in arrears was chosen as the group of abandonments to be explained. This was done because the data concerning more recent abandonments are most likely to be contaminated with owners temporarily in arrears who do not intend to abandon their buildings, while the data concerning buildings more that 3 years in arrears are affected by the fact that varying numbers of buildings in different regions of the city will have already been foreclosed and therefore out of the sample.

We present results explaining abandonment rates for both 1976 and 1978. For 1976, the mean probability of a building being between 18

\footnotetext{
${ }^{15}$ Several neighborhoods containing no population (e.g., parks and cemeteries) and neighborhoods for which data were missing were dropped from the sample. All of the data come from special reports on neighborhoods put together by the New York City Department of City Planning from data in the MISLAND (Standardized Computer Report Package for Land Use, Housing and Demographic Information) system. The special studies are entitled "Neighborhood Statistical Profiles," prepared by Cooperative Community Planning, NYC Department of City Planning (1978), and "Trends in Tax Arrears," NYC Department of City Planning. The data were assembled for a 1980 study of property taxes by the New York University Graduate School of Public Administration (Dick Netzer, Project Director, entitled "Real Property Tax Policy for New York City").
} 
TABLE 1

Data Means and Standard Deviations

\begin{tabular}{lccc}
\hline & Date & Means & Standard deviations \\
\hline Probability of abandonment & 1976 & $6.1 \%$ & $5.8 \%$ \\
& 1978 & $4.8 \%$ & $6.7 \%$ \\
Assessed value & $1974-1976$ & $\$ 30,000$ & $\$ 52,000$ \\
Market value & $1974-1976$ & $\$ 59,000$ & $\$ 64,500$ \\
SFHU & 1970 & 0.43 & 0.42 \\
OLTN & 1978 & 0.050 & 0.11 \\
OLD & 1970 & 0.57 & 0.25 \\
$W L F R$ & 1974 & 0.022 & 0.030 \\
$I N C O M E$ & 1974 & $\$ 4600$ & $\$ 6200$ \\
PQD $_{i}$ & & $\$ 6800$ & $\$ 3800$
\end{tabular}

months and 3 years in arrears was 0.062 . For 1978, the figure is 0.055 . (See Table 1 for data means and standard deviations.) In comparison, the mean probability of a building being in tax arrears from 9 months until foreclosure (i.e., being in any of the three groups of buildings in arrears) was 0.145 in 1976 and 0.143 in 1978 . Henceforth, references to the probability of abandonment will refer to the probability of a building being between 18 months and 3 years in tax arrears. ${ }^{16}$

There are three groups of explanatory variables. The first includes the property tax and average rent variables whose theoretical derivation is described above. For each neighborhood in the sample, the number of buildings sold in arm's-length transactions between July 1974 and July 1976 was available, as well as the average assessed value and average market value (sales price) for all buildings that were sold. (The average number of sales in a neighborhood was 780 .) To measure average property tax liability for buildings in neighborhood $i$, we multiplied the average assessed value of buildings sold in the neighborhood times the citywide statutory property tax rate of $8.75 \%$. The resulting average property tax liability per building in neighborhood $i$ is denoted $T D_{i}$. The assessed value of buildings sold is likely to differ from that of buildings abandoned, since the sample of buildings sold is drawn from a population which excludes abandoned buildings. However, I assume here that the resulting bias is low since the probability of abandonment is itself fairly low.

The average rent variable, $\widehat{P Q D}_{i}$, is derived as explained above from neighborhood data concerning average property tax liability and average

\footnotetext{
${ }^{16}$ The results of explaining abandonment rates in the other categories or of explaining overall abandonment rates were very similar to the results given below.
} 
market value of buildings sold during 1974-1976. The parameter values used to solve for $\widehat{P Q D}_{i}$ from (9) are $d=0.05, r=0.04$, and $g=4$.

The second group of variables measures characteristics of the buildings in each neighborhood. Together they constitute the vector of neighborhood characteristics, $G_{i}$. The physical variables are $O L D$, the percentage of buildings in the neighborhood built before 1939; OLTN, the percentage of buildings in the neighborhood that are old law tenements; and SFHU, the percentage of housing units in the neighborhood that are in one- or two-family houses. The variables $O L D$ and $S F H U$ are for 1970 , while $O L T N$ is for 1978 . Since these variables change extremely slowly over time, the wide range of dates was not considered to be a problem. Also since each variable is available for only a single year, the same data are used to explain both abandonment rates in 1976 and lagged abandonment rates in 1978.

Finally, the third group of variables measures the characteristics of people in the neighborhood. These are $W L F R$, the percentage of population in the neighborhood receiving public assistance, and INCOME, a measure of mean income of households in the neighborhood. Both variables are for 1974.

The welfare variable is of particular interest because it has been suggested by Salins [6] that the presence of families on welfare is an important determinant of housing abandonment in New York. Salins argues that the New York system of providing a separate and relatively generous welfare grant for housing alone (the "shelter allowance") means that welfare families have an incentive to move frequently, since a change in family status may increase the allowable housing grant, although the household can take advantage of the change only by moving. (Moving costs also are covered.) Further, because rent control holds down rent levels, welfare families have access to middle-class neighborhoods. But welfare families are destructive of housing because they often cash their shelter allowance checks rather than giving them to landlords. Finally, landlords are often unable to evict tenants who do not pay rent, both because the courts are slow and because the courts often do not allow evictions if buildings have code violations, even if the latter are tenant-created. When welfare families are finally evicted, their moving costs are paid by the welfare system, no attempt is made to penalize them for their nonpayment of rent, and a new cycle starts in a new apartment. Thus the argument is that welfare families moving into a neighborhood destabilize it by their frequent moves, damage the buildings, cause nonwelfare families to flee and, finally, set off a cycle of abandonments which then spreads to contiguous blocks. We can examine here the hypothesis that the presence of welfare families is an important determinant of the level of abandonment in the neighborhood. The sign of the welfare variable is expected to be positive. 
TABLE 2

Logit Regression Results Explaining Probability of Abandonment

\begin{tabular}{|c|c|c|c|c|c|c|}
\hline & \multicolumn{3}{|c|}{1976} & \multicolumn{3}{|c|}{1978} \\
\hline & $\begin{array}{l}\text { Logit } \\
\text { results }\end{array}$ & $\begin{array}{l}\text { Coeffi- } \\
\text { cients }\end{array}$ & $\begin{array}{l}\text { Elasti- } \\
\text { cities }\end{array}$ & $\begin{array}{l}\text { Logit } \\
\text { results }\end{array}$ & $\begin{array}{l}\text { Coeffi- } \\
\text { cients }\end{array}$ & $\begin{array}{l}\text { Elasti- } \\
\text { cities }\end{array}$ \\
\hline$T D$ & $\begin{array}{l}-1.30 \\
(0.0376)\end{array}$ & 0.0488 & 2.12 & $\begin{array}{l}-1.52 \\
(0.0485)\end{array}$ & 0.0298 & 1.65 \\
\hline$N$ & 257 & & & 245 & & \\
\hline SSE & 484 & & & 725 & & \\
\hline $\begin{array}{l}\text { Dependent } \\
\text { variable mean }\end{array}$ & -3.12 & & & -3.62 & & \\
\hline
\end{tabular}

Table 2 gives the results of estimating (15') for 1976 and $1978 .{ }^{17}$ The first entry of the table, labeled logit results, gives the raw logit coefficient of the term $\left[\left(e^{-0.36} \overline{P Q D}_{i} / T D_{i}\right)-1\right]$. (Standard errors are in parentheses.) The second entry of the table, labeled coefficients, gives the change in the probability of abandonment per unit change in property tax liability, or $\partial \rho_{i} / \partial T D_{i}$. This figure is derived from the raw logit result via the following steps: (1) the raw logit result is multiplied by $\bar{\rho}(1-\bar{\rho})$, where $\bar{\rho}$ is the mean probability of abandonment; (2) the derivative of the term $\left[\left(e^{-0.36} \widehat{P Q D}_{i} / T D_{i}\right)-1\right]$ with respect to $T D_{i}$ (holding $\widehat{P Q D}_{i}$ constant) is evaluated at the mean values of $\widehat{P Q D}_{i}$ and $T D_{i}$; and (3) the results of steps (1) and (2) are multiplied together. Finally, the third entry of the table transforms the coefficient into an elasticity of changes in property tax liability on the probability of abandonment, evaluated at the means of $T D_{i}$ and $\rho_{i}$. Thus the tax coefficient in 1976 indicates that a $\$ 1000$ increase in average property tax liability causes an increase of 0.05 in the rate of abandonment, holding rents constant. The elasticity term indicates that a $1 \%$ increase in property tax liability causes a $2.1 \%$ increase in the probability of abandonment.

The results suggest that property taxes have a very large and significant effect on abandonment rates. A $1 \%$ rise in property taxes causes an increase of about $2.1 \%$ in the abandonment rate immediately (1976 results). The lagged effect of the rise in property taxes is somewhat smaller but equally significant - the elasticity of the abandonment rate with respect to property taxes for 1978 is 1.65 . To illustrate this effect, suppose that the average building in the sample had its assessed value reduced by $\$ 1000$, from $\$ 30,300$ to $\$ 29,300$. This change would reduce average property tax liability

\footnotetext{
${ }^{17} R^{2}$ values are not given in the tables, since the equations estimated do not have constant terms.
} 
TABLE 3

Logit Regression Results Explaining Probability of Abandonment with Heteroscedasticity Correction

\begin{tabular}{|c|c|c|c|c|c|c|}
\hline & \multicolumn{3}{|c|}{1976} & \multicolumn{3}{|c|}{1978} \\
\hline & $\begin{array}{l}\text { Logit } \\
\text { results }\end{array}$ & $\begin{array}{l}\text { Coeffi- } \\
\text { cients }\end{array}$ & $\begin{array}{l}\text { Elasti- } \\
\text { cities }\end{array}$ & $\begin{array}{l}\text { Logit } \\
\text { results }\end{array}$ & $\begin{array}{l}\text { Coeffi- } \\
\text { cients }\end{array}$ & $\begin{array}{l}\text { Elasti- } \\
\text { cities }\end{array}$ \\
\hline$T D$ & $\begin{array}{c}-1.539 \\
(0.107)\end{array}$ & 0.0579 & 2.51 & $\begin{array}{c}-1.77 \\
(0.137)\end{array}$ & 0.0528 & 2.93 \\
\hline OLTN & $\begin{array}{c}0.881 \\
(0.505)\end{array}$ & 0.0372 & 0.0301 & $\begin{array}{c}1.06 \\
(0.638)\end{array}$ & 0.0355 & 0.0367 \\
\hline$O L D$ & $\begin{array}{c}0.058 \\
(0.152)\end{array}$ & 0.00245 & 0.0228 & $\begin{array}{c}0.142 \\
(0.197)\end{array}$ & 0.00476 & 0.0566 \\
\hline$S F H U$ & $\begin{array}{c}0.140 \\
(0.0927)\end{array}$ & 0.00592 & 0.0414 & $\begin{array}{r}0.0911 \\
(0.119)\end{array}$ & 0.00305 & 0.0272 \\
\hline$W L F R$ & $\begin{array}{c}6.15 \\
(1.49)\end{array}$ & 0.260 & 0.0924 & $\begin{array}{c}6.46 \\
(1.90)\end{array}$ & 0.216 & 0.0982 \\
\hline$I N C$ & $\begin{array}{c}-4.75 e^{-7} \\
\left(7.36 e^{-6}\right)\end{array}$ & $-2.01 e^{-8}$ & -0.0356 & $\begin{array}{c}-1.40 e^{-6} \\
\left(9.29 e^{-6}\right)\end{array}$ & $-4.69 e^{-8}$ & -0.00449 \\
\hline$N$ & 257 & & & 245 & & \\
\hline $\begin{array}{l}\text { SSE } \\
\text { Dependent }\end{array}$ & 441 & & & 667 & & \\
\hline variable mean & -3.12 & & & -3.62 & & \\
\hline
\end{tabular}

by $3.3 \%$ and would thus cause the probability of abandonment to fall by about $7 \%$ in 1976 , or from a rate of $6.2 \%$ to a rate of $5.8 \%$.

The error terms of the regressions reported in Table 2 were tested for heteroscedasticity by regressing the residuals squared against the vector of neighborhood effects, with all variables in $\log$ form. Since the results indicated significant heteroscedasticity (using an $F$ test) in both the 1976 and 1978 regressions, the equations were reestimated according to the specification in (15"). The results are reported in Table 3.

The first row of Table 3, labeled $T D$, has the same interpretation as in Table 2. Note that the tax effects on abandonment are similar to those in Table 2 and are highly significant. The elasticity of the abandonment rate with respect to property tax liability is slightly larger than in Table 2; it is 2.5 for 1976 and 2.9 for 1978 .

Results given for the other variables are interpreted as follows. Taking the old law tenement variable as an example, the first entry is the raw logit coefficient of the term $\operatorname{OLTN}\left[\left(e^{-0.36} \widehat{P Q D_{i}} / T D_{i}\right)-1\right]$ and the second and third entries are the coefficient $\partial \rho_{i} / \partial O L T N_{i}$ and the elasticity of changes in $O L T N$ on the probability of abandonment. The coefficient $\partial \rho_{i} / \partial O L T N_{i}$ is derived from the raw logit result by multiplying the raw logit result by $\bar{\rho}(1-\bar{\rho})$ and by $\left[\left(e^{-0.36} \overline{P Q D_{i}} / T D_{i}\right)-1\right]$, evaluated at the means of $P Q D_{i}$ 
and $T D_{i}$. The elasticity is evaluated at the mean values of $\rho_{i}$ and $O L T N_{i}$. Thus the effect in 1976 of a one percentage point increase in the proportion of housing that is old law tenements on the abandonment rate is 0.037 and the effect of a $1 \%$ increase in the proportion of housing that is old law tenements is a $0.03 \%$ increase in the abandonment rate.

Examining the effects of the nontax variables, it is interesting that none of the physical variables pertaining to the housing stock appears to be strongly related to abandonment. In both regressions, none of these variables is significantly related to the abandonment rate and $S F H U$ has the wrong sign. Thus the results do not support the hypothesis that the types of buildings present in particular neighborhoods are a significant determinant of the abandonment rate, i.e., structures do not appear to be abandoned by their owners merely because they are outdated building types or retained because they are popular building types.

In contrast, the welfare effects are consistently significant but small. A $1 \%$ increase in the proportion of the population receiving welfare causes a $0.092 \%$ increase in the abandonment rate in the 1976 equation and a $0.098 \%$ increase in the 1978 equation. Finally, the income variable has the correct sign but is insignificant in both equations.

Comparing the importance of the welfare variable with that of the property tax variable, in both equations the elasticity of the abandonment rate with respect to property taxes is more than 20 times as large as the elasticity of abandonment with respect to the welfare population. In addition, property tax liabilities are a variable which is directly under the control of the city government, unlike that of the welfare population. We now turn to the issue of using property tax assessments as a policy variable to reduce abandonment rates.

\section{PROPERTY TAX POLICY ISSUES}

The regression results are quite striking in that they suggest that property tax and assessment levels are important determinants of abandonment rates. In addition to taxes being the largest factor, taxes also differ from other variables in that they are policy instruments controlled by cities. The results suggest that cities can have an important impact on abandonment rates by introducing a policy of systematic downward assessment of buildings in blighted neighborhoods - and by following up abandonments with a policy of immediate foreclosure once property taxes go into arrears. Such an approach appears to be much more direct and feasible than attempting to reduce abandonment indirectly by replacing old buildings with new or by raising public assistance payments to poor families.

To illustrate, examine one blighted neighborhood in the sampleBrownsville in Brooklyn - which was among the several worst neighborhoods in the sample. Its probability of abandonment as of 1978 was $17 \%$. A 
total of 55\% of its buildings were in tax arrears by 9 months or more in 1978. The average market value of buildings sold there in 1976-1978 was $\$ 24,000$ and the average assessed value of buildings sold was $\$ 17,000$. Suppose that a policy were introduced of systematically reducing assessments on all buildings in areas such as Brownsville. (The policy could be applied generally to large areas such as neighborhoods or could be applied to smaller areas such as census tracts or blocks.) If all assessments in the neighborhood were reduced by $\$ 1000$ per building, the average property tax liability in Brownsville would fall by one-seventeenth, or $6 \%$. Using the results in Table 2 for 1976, the model predicts that this change would cause the abandonment rate in Brownsville to fall by $13 \%$ or from a rate of $17 \%$ to a rate of $14.8 \%$.

What are the costs and benefits of such a policy? The cost to the city would be about $\$ 90$ per year in foregone taxes per building actually paying property taxes. There are 2700 residential properties in Brownsville, of which about 1200 were paying property taxes as they came due in 1978 . Thus the policy would cost the city about $\$ 109,000$ per year in foregone taxes for the entire neighborhood.

The total benefit of the policy is more difficult to calculate, since it includes both increased tax revenues on buildings not abandoned and reduced costs to the city of operating buildings that are in rem and/or relocating welfare families that are forced to move. Examining the first, the regression results imply that the policy will cause 60 fewer buildings in Brownsville to be abandoned in 1978. Suppose that these buildings have assessments equal to the average for Brownsville. Tax revenues on these buildings at the reduced assessment level amount to $\$ 86,000$ per year.

Second, if the 60 buildings were abandoned, some of them would be operated by the city under the in rem program. In 1982, New York City spent $\$ 147$ million (net of rents collected) operating 3800 abandoned buildings, or a cost of $\$ 37,800$ per building per year. ${ }^{18}$ Suppose that only one-quarter of the newly abandoned buildings would be operated by the city $^{19}$ and that the equivalent cost in 1978 would have been only half as great due to inflation in the intervening period. In that case, not operating 15 in rem buildings would save the city $\$ 13,900$ per building, for a total savings of $\$ 208,000$ in 1978 .

Thus in our example, reducing all assessments in Brownsville by $\$ 1000$ would cost the city $\$ 109,000$ per year in reduced property tax receipts, but

\footnotetext{
${ }^{18}$ See "Rundown Buildings Called Housing Resource," New York Times, May 2 (1983). The cost per person living in abandoned buildings is $\$ 1470$ per year.

${ }^{19}$ Schur [7] indicates that as of 1980 , New York City had taken over 13,000 buildings under the in rem program, of which 4000 were occupied. This implies an occupancy rate of $31 \%$. A slightly lower rate of $25 \%$ is used in the calculation, since the city sometimes consolidates tenants of partially occupied in rem buildings.
} 
would save it $\$ 86,000$ per year in property taxes paid by owners of buildings that would otherwise be abandoned, plus $\$ 108,000$ per year in foregone operating costs of in rem buildings. The benefit/cost ratio is 2.7 for such a policy. Further, benefits could be expected to rise over several years as the number of buildings not abandoned due to the policy rises.

Obviously these calculations are crude. ${ }^{20}$ They would also be different for other cities having different policies toward abandoned housing and displaced families. But the results suggest that property taxes are an important factor in causing ownership abandonment of housing in blighted neighborhoods. Cities have considerable control over property taxes-they set both assessment levels and the grace period until foreclosure. This study suggests that a systematic policy of cutting property tax assessments in blighted neighborhoods but taking over properties as soon as tax payments start to go into arrears could have significant downward effects on rates of ownership abandonment.

\section{REFERENCES}

1. B. Bender, The determinants of housing demolition and abandonment, South. Econom. J., 46, 131-144 (1979).

2. B. Bender, Urban housing density and the price of housing services, J. Urban Econom., 9, 80-84 (1981).

3. G. E. Peterson, The property tax and low income housing markets, in Property Tax Reform (G. E. Peterson, Ed.). John C. Lincoln Institute and Urban Institute, Washington, D.C. (1973).

4. G. E. Peterson, A. Solomon, H. Madjid, and W. C. Apgar, Jr., "Property Taxes, Housing and the Cities," Lexington Books, Lexington, Mass. (1973).

5. R. Pindyck and D. Rubinfeld, "Econometric Models \& Economic Forecasts," 2nd ed., McGraw-Hill, New York (1981).

6. P. Salins, "The Ecology of Housing Destruction," New York Univ. Press, New York (1980).

7. R. Schur, Growing lemons in the Bronx, Working Paper for a New Society (July/Aug. 1980).

8. B. A. Smith, The supply of urban housing, Quart. J. Econom., XC, 389-405 (1976).

9. M. A. Stegman, "The Dynamics of Rental Housing in New York City," Center for Urban Policy Research, New Brunswick, N.J. (1982).

10. M. A. Stegmen, "Housing Investment in the Inner City," MIT Press, Cambridge, Mass. (1972).

11. G. Sternlieb, “The Tenement Landlord," Rutgers Univ. Press, New Brunswick, N.J. (1966).

12. G. Sternlieb and R. W. Burchell, "Residential Abandonment: The Tenement Landlord Revisited," Center for Urban Policy Research, New Brunswick, N.J. (1973).

\footnotetext{
${ }^{20}$ Benefits are overestimated since the city probably maintains in rem buildings at a higher standard than would private owners, but are underestimated since the city also pays to house residents displaced from abandoned buildings in shelters and private hotels. The latter type of housing is even more expensive.
} 